\title{
Ion Laser Plasmas
}

\author{
WILLIAM B. BRIDGES, FELLOW, IEEE, ARTHUR N. CHESTER, MEMBER, IEEE, \\ A. STEVENS HALSTED, MEMBER, IEEE, AND JERALD V. PARKER, MEMBER, IEEE
}

\author{
Invited Paper
}

\begin{abstract}
The typical noble gas ion laser plasma consists of a high-current-density glow discharge in a noble gas, in the presence of a magnetic field. Typical CW plasma conditions are current densities of 100 to $2000 \mathrm{~A} / \mathrm{cm}^{2}$, tube diameters of 1 to $10 \mathrm{~mm}$, filling pressures of 0.1 to 1.0 torr, and an axial magnetic field of the order of $1000 \mathrm{G}$. Under these conditions the typical fractional ionization is about 2 percent and the electron temperature between 2 and $4 \mathrm{eV}$. Pulsed ion lasers typically use higher current densities and lower operating pressures.

This paper discusses the properties of ion laser plasmas, in terms of both their external discharge parameters and their internal ion and excited state densities. The effect these properties have on laser operation is explained. Many interesting plasma effects, which are important in ion lasers, are given attention. Among these are discharge nonuniformity near tube constrictions, extremely high ion radial drift velocities, wall losses intermediate between ambipolar diffusion and free fall, gas pumping effects, and radiation trapping. The current status of ion laser technology is briefly reviewed.
\end{abstract}

\section{INTRODUCTION}

$\mathrm{T}$ HEE ION LASER is one of the most important practical sources of visible and ultraviolet coherent light presently known. In addition, it incorporates a gaseous plasma exhibiting a number of interesting properties besides laser action. This paper briefly reviews some of the principal characteristics of ion laser plasmas.

Section I summarizes the operating principles and output characteristics of the most important ion lasers. Section II presents a basic description of the $\mathrm{CW}$ argon ion laser plasma as an example, covering mainly those aspects that are reasonably well understood at present. Section III discusses some of the important plasma phenomena which also occur in ion laser plasmas but which are understood only qualitatively. This discussion includes both technological problems and their underlying physical effects.

\section{A. Characteristics of Ion Lasers}

An ion laser plasma generally consists of a long narrow cylindrical high-density glow discharge. The optical radiation from the discharge is directed repeatedly through the glow region by mirrors placed at each end of the tube. The positive column of the discharge plasma constitutes the laser medium and amplifies the radiation. Many different excitation techniques have been used to produce a glow discharge of the proper characteristics. Among these are pulsed and CW dc discharges using electrodes (both hot and

Manuscript received January 16, 1971. This invited paper is one of a series planned on topics of general interest-The Editor.

W. B. Bridges, A. N. Chester, and J. V. Parker are with the Hughes Research Laboratories, Malibu, Calif. 90265.

A. S. Halsted is with the Electron Dynamics Division, Hughes Aircraft Company, Torrance, Calif. 90509. cold cathode), pulsed dc discharges using electrodeless magnetic induction coupling, pulsed and CW RF discharges using induction coupling with electric fields both longitudinal and transverse to the long dimension of the plasma, microwave cyclotron resonance discharges, beam-generated plasmas, and pinch-generated plasmas (both $z$-and $\theta$-pinch types). In this brief review it would be impossible to cover the detailed characteristics produced by each excitation method. Representative examples must necessarily be chosen. It is fortunate, however, that the method of producing the plasma seems to have little effect on the laser properties; CW ion lasers exhibit roughly the same overall characteristics whether produced by a hot cathode dc discharge or an RF induction excited system. Pulsed lasers are likewise relatively independent of the excitation means. In much of the discussion following, the argon ion laser [1] [3] will be taken as the example, since the largest body of information exists for this most popular laser type.

For a typical ion laser the most important physical processes producing the laser action are as follows. In the glow discharge, approximately 1 percent of the atoms are ionized. Electrons with a mean energy of 2 to $4 \mathrm{eV}$ collide with ground state ions and produce excited ions, including ionic states that constitute the upper and lower laser levels. The excitation cross sections and radiative lifetimes are such that the steady-state population density of the upper laser levels in the discharge is much larger than the density of the lower laser levels. This population inversion produces optical gain and laser action, typically on radiative transitions between several pairs of upper and lower levels. The laser output wavelengths depend on the choice of gas, the operating conditions, or the use of wavelength-selective laser mirrors.

The great practical importance of ion lasers derives from several useful characteristics. The optical gain of the ion laser plasma is very high, typically $>1 \mathrm{~dB} / \mathrm{m}(23$ percent $/ \mathrm{m})$ [3]-[7] and as high as $13 \mathrm{~dB} / \mathrm{m}$ in argon [8]; this makes it very easy to secure laser oscillation even when mirrors and windows are not of the highest optical quality. In addition, ion lasers produce numerous laser lines that lie in or near the visible portion of the spectrum; at present, 437 different wavelengths have been observed, originating from 29 different elements, and ranging in wavelength from 0.2358 to $1.555 \mu \mathrm{m}$ [9]. Finally, the most important laser lines (and more than half of all observed lines) employ only noble gases in the discharge tube, and the chemical inertness of these gases simplifies many aspects of tube technology. 
TABLE I

Operating Conditions of Typical Ion Lasers

\begin{tabular}{lcccc}
\hline \hline & $\begin{array}{c}\text { Tube } \\
\text { Diameter } \\
(\mathrm{mm})\end{array}$ & $\begin{array}{c}\text { Tube } \\
\text { Length } \\
\text { (cm) }\end{array}$ & $\begin{array}{c}\text { Discharge } \\
\text { Current (A) }\end{array}$ & Gas Fill Pressure \\
\hline $\begin{array}{c}\text { Pulsed, noble } \\
\text { gas }\end{array}$ & $2-10$ & $10-200$ & $100-1000$ & $10-50 \mathrm{mtorr}$ \\
$\mathrm{CW}$, noble gas & $1-12$ & $10-50$ & $10-100$ & $50-1000 \mathrm{mtorr}$ \\
$\mathrm{CW}, \mathrm{He}-\mathrm{Cd}$ & 3 & 150 & $0.04-0.10$ & $\begin{array}{c}2-10 \mathrm{mtorr} \mathrm{Cd} \\
\text { plus 2-8 torr He }\end{array}$ \\
& & & &
\end{tabular}

The operating conditions of the most useful ion lasers are summarized in Table I. The simplest type of ion laser is that operated with a low-duty-cycle pulsed discharge, generally with pulses $1-100 \mu$ s in duration and repetition rates up to a few hundred pulses per second. A typical pulsed tube consists of a long glass, quartz, or ceramic capillary with an anode and a cold cathode located in sidearms at each end of the tube. An external optical resonator is usually employed, with Brewster's angle windows mounted on the discharge tube to minimize reflective loss. The laser output generally follows the current pulse. However, if the current density and the pulse length become too great, laser action may be quenched by loss of gas density in the capillary (caused by thermal driveout and gas pumping effects) or by radiation trapping of the lower laser level, as discussed later. In addition, at long pulse lengths the capillary may be thermally destroyed unless adequately cooled.

The second type of ion laser listed in Table $\mathrm{I}$ is the CW noble gas ion laser. The earliest $\mathrm{CW}$ ion lasers used a watercooled quartz capillary to permit high average input power to the discharge. Gas pumping caused by electron and ion drift motion in the positive column led to substantial pressure gradients along the tube. To keep the discharge maintained at a convenient voltage it was found desirable to equalize the pressure at the cathode and anode by connecting them with a gas return path, which consisted of a glass tube with sufficient conductance to permit easy gas flow but long enough to prevent a discharge from striking through it. A photograph of such a tube appears in [10]. The addition of a magnetic field (about $1 \mathrm{kG}$ ) with field lines parallel to the optical axis increases the laser output, particularly from tubes of less than 6-mm diameter, and a magnetic field is usually used with such tubes. The higher current densities and extended lifetime currently demanded of ion lasers have led to the development of highly engineered metal-ceramic tubes of the type shown in Fig. 1.

The third major type of ion laser, typified by the $\mathrm{CW}$ helium-cadmium laser, operates at modest power levels and does not require special cooling. The most popular version of this laser [11] resembles in construction the familiar helium-neon lasers except for the addition of a sidearm containing cadmium metal. The vapor pressure of cadmium in the discharge is controlled by heating this sidearm. Both zinc and selenium ion lasers have been made in this form to date (see tabulation and references in [9]).

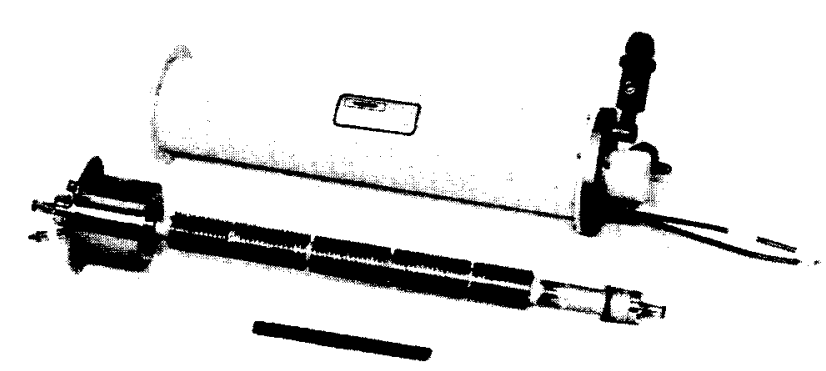

Fig. 1. A high-performance metal-ceramic argon ion laser discharge tube with its associated magnet. Metal cooling fins surround the ceramic section. (Hughes Electron Dynamics Division.)

The output characteristics of the most extensively studied practical ion lasers are summarized in Table II. The argon ion laser, with blue and green output, has undergone the most advanced development to date. The newest among the sources listed is the xenon IV laser, ${ }^{1}$ which demonstrates a high-power pulsed mode of operation that is, so far, unique among ion lasers. The high electrical efficiencies (exceeding 0.1 percent) and the availability of multiwatt output at a great variety of wavelengths (of which only a few are listed here) make ion lasers important sources of coherent radiation in the visible and near UV.

The effect of length and tube diameter on laser output power and efficiency is illustrated in Fig. 2 for the bluegreen lines of the argon ion laser. In this figure the $\mathrm{CW}$ laser output power per unit length of discharge column is plotted as a function of the parameter $J R$, where $J$ is discharge current density and $R$ is the inner tube radius. For most curves, the externally applied magnetic field and the gas filling pressure have been adjusted to maximize the laser output at each value of current used. The curves are marked to indicate the tube diameter, which ranges from 1.2 to 12 $\mathrm{mm}$. The abscissa is marked to indicate approximate input power per unit length of discharge, since the input power can be correlated with the quantity $J R$ in a manner roughly independent of tube radius. The lines of constant electrical efficiency indicate the ratio of laser output to electrical input for the positive column only; thus the indicated efficiencies of Fig. 2, unlike those of Table II, do not include electrode potential drop, electrode heater power (if needed), or electromagnet power (if needed). The great variation that is apparent in the curves of Fig. 2 represents, in part, the gradual improvement of ion laser technology, with respect to both electrical efficiency and power output from a given length tube.

The highest reported power per unit length is $105 \mathrm{~W} / \mathrm{m}$ from a $12-\mathrm{mm}$ tube [12], and the highest efficiency is 0.16 percent from a $6.35-\mathrm{mm}$ tube [13]. Large diameter tubes

\footnotetext{
${ }^{1}$ The roman numeral following the element name or symbol refers to the ionization state of the species from which the spectroscopic line arises The numeral is one larger than the ionization. Thus " $\mathrm{Xe}^{3+}$ " is equivalent to "Xe IV" since the first spectrum of xenon, $\mathrm{Xe} \mathrm{I}$, arises from the neutral atom.
} 
TABLE II

Ion Laser Performance: 1970 State of the Art

\begin{tabular}{|c|c|c|c|c|c|}
\hline Lasing Species & Lasing Mode & Strongest Wavelengths $(\mu \mathrm{m})$ & Output Power & $\begin{array}{l}\text { Output Power per } \\
\text { Unit Length }\end{array}$ & $\begin{array}{c}\text { Overall Electrical } \\
\text { Efficiency }(\%)\end{array}$ \\
\hline Ar Il & $\mathrm{CW}$ & $0.4880,0.5145$ & $120 \mathrm{~W}^{\mathrm{2}}$ & $105 \mathrm{~W} / \mathrm{m}^{\mathrm{b}}$ & $0.16^{\mathrm{c}}$ \\
\hline $\mathrm{Kr}$ II & $\mathrm{CW}$ & 0.6471 & $\sim 10 W^{n}$ & $5 \mathrm{~W} / \mathrm{m}^{\mathrm{a}}$ & $\sim 0.01^{\mathbf{a , d}}$ \\
\hline $\mathrm{Cd} I I$ & $\mathrm{CW}$ & 0.4416 & $0.2 \mathbf{W}^{e}$ & $0.14 \mathrm{~W} / \mathrm{m}^{\mathrm{e}}$ & $0.09^{f}$ \\
\hline Cd II & $\mathrm{CW}$ & 0.3250 & $0.02 \mathrm{~W}^{e}$ & $0.014 \mathrm{~W} / \mathrm{m}^{\mathrm{e}}$ & $\sim 0.01^{e, f}$ \\
\hline Ar III & $\mathrm{CW}$ & $0.3638,0.3511$ & $5 \mathbf{W}^{\mathbf{k}}$ & $5 \mathrm{~W} / \mathrm{m}$ & $0.01 *$ \\
\hline Xe IV & $\mathrm{CW}$ & $\begin{array}{l}0.4954-0.5395 \\
(5 \text { lines })\end{array}$ & $0.5 \mathrm{~W}^{\mathrm{h}}$ & $1 \mathrm{~W} / \mathrm{m}^{\mathrm{h}}$ & $<0.01^{\mathrm{h}}$ \\
\hline Xe IV & pulsed & $\begin{array}{l}0.5395,0.5353, \\
0.5260\end{array}$ & $\begin{array}{l}0.4 \mathrm{~J} / \text { pulse }^{\mathrm{i}} \\
(20 \mathrm{~kW} \text { peak })\end{array}$ & $0.14 \mathrm{~J} / \mathrm{m}^{\mathrm{i}}$ & $\sim 0.3^{i, j}$ \\
\hline
\end{tabular}

' K. Banse, H. Boersch, G. Herziger, G. Schäfer, and W. Seelig, Z. Angew. Phys., vol. 26, 1969, pp. 195-200.

${ }^{b}$ H. Boersch, J. Boscher, D. Hoder, and G. Schäfer, Phys. Lett., vol. 31A, 1970, pp. 188-189.

c J. R. Fendley, Jr., Proc. 4th DOD Conf. Laser Technology (San Diego, Calif., Jan. 1970), vol. 1, pp. 391-398 (unpublished).

${ }^{d}$ W. B. Bridges and A. S. Halsted, Hughes Res. Labs., Malibu, Calif., Tech. Rep. AFAL-TR-67-89, May 1967 (unpublished); DDC accession no. AD-814-897.

- J. P. Goldsborough, Appl. Phys. Lett., vol. 15, 1969, pp. 159-161.

${ }^{f}$ W. T. Silfvast, Appl. Phys. Lett., vol. 13, 1968, pp. 169-171. The efficiency of 9.02 percent given in Silfvast is a misprint and should instead be 0.09 percent.

W. B. Bridges and G. N. Mercer, Hughes Res. Labs., Malibu, Calif., Rep. ECOM-0229-F, Oct. 1969 (unpublished); DDC accession no. AD-861-927.

" - "CW operation of high ionization states in a xenon laser," IEEE J. Quantum Electron. (Corresp.), vol. QE-5, Sept. 1969, pp. 476-477.

i W. W. Simmons, private communication, July 31, 1970.

j Pulse efficiency is defined as peak laser output power, divided by the product of peak tube current and initial applied voltage.

J. R. Fendley, Jr., private communication, Jan. 1970.

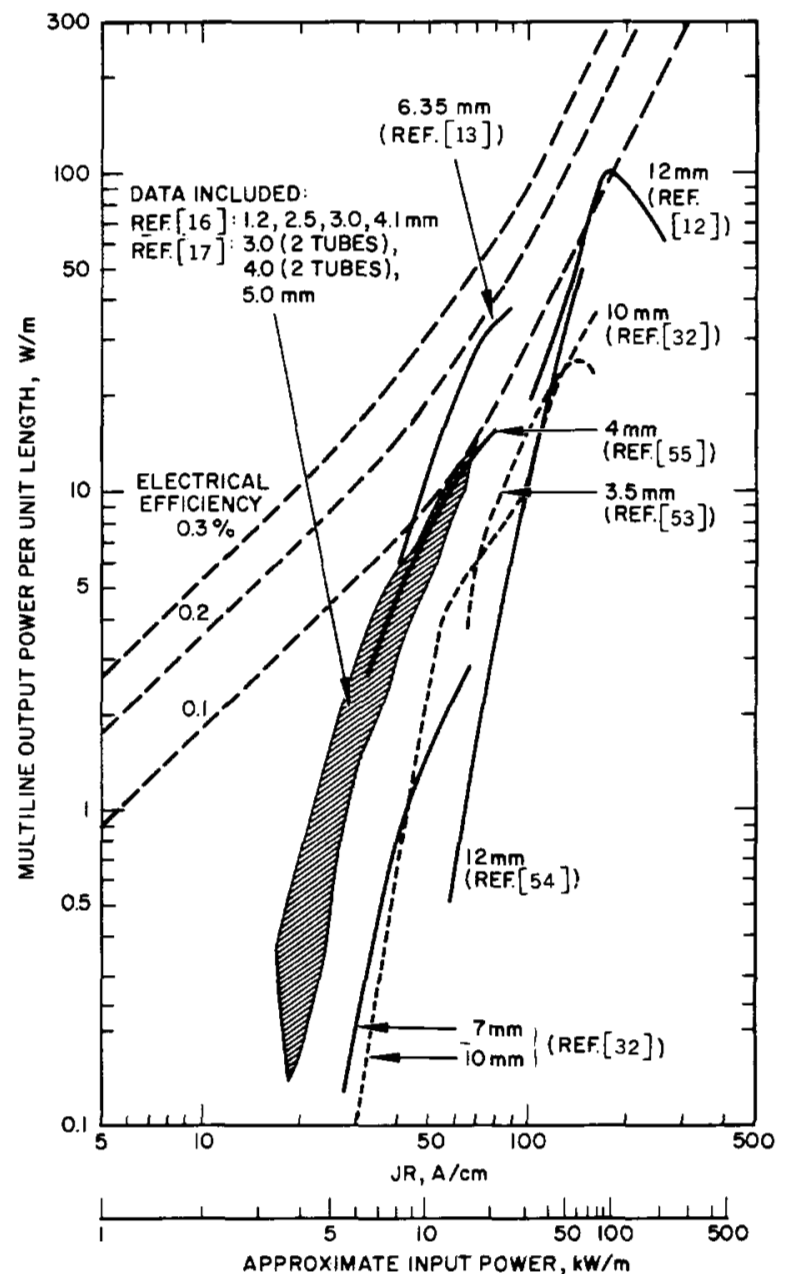

Fig. 2. Summary of reported power output characteristics of CW Ar II ion lasers from the following sources: Fig. 4 in [16]; Fig. 1 in [53]; Fig. 13 in [17]; Fig. 5 in [54]; Figs. 10 and 14 in [32]; Fig. 6 in [13]; Fig. 1 in [12]; and Table I ( $4-\mathrm{mm}$ by 18 -in tube) in [55]. Indicated electrical efficiency is calculated for positive column only, using axial electric field data from Fig. 32 in [17]; Figs. 4 and 14 in [32]; and eq. (3.1) in [26].
( $\sim 10-12 \mathrm{~mm}$ ) have some advantages-they require less or no external magnetic field for efficient operation; their larger wall area eases the thermal load on wall materials; and the larger optical beam size reduces the flux density that must be withstood by optical components such as windows and mirrors. However, many applications require that the laser operate in a single transverse optical mode, so that the laser output is completely phase coherent across the beam front. This is very difficult to achieve in such a larger diameter tube [14] and limits the usefulness of this type of ion laser. An additional disadvantage of the larger bore tubes is that the laser gain and output power decrease with increasing tube diameter [6], [17]; thus many lines will not oscillate at all in a larger diameter tube, and those that will oscillate require higher quality windows and mirrors for efficient operation.

The relative merits of large and small diameter ion-laser tubes may be summarized as follows. When maximum power per unit length is desired on the strongest laser transitions (i.e., the Ar II, $\mathrm{Kr}$ II, and Xe IV lines of Table II), the large diameter tubes are an appropriate choice. When minimum beam divergence (from single transverse mode operation), less output power $(\sim 1 \mathrm{~W})$, or other laser transitions are required, a small diameter tube is usually the best choice. When maximum overall electrical efficiency is required, the choice of tube geometry will depend upon the wavelengths desired and other operational requirements.

Not surprisingly, the ranges of plasma characteristics that have been most fully explored correspond to the operating conditions of practical devices, as summarized in Tables I and II and in Fig. 2. We will proceed now to give a more complete description of what is known about the ion laser itself. Our discussion will center mainly on the most highly developed ion laser, the blue-green lines of Ar II. 


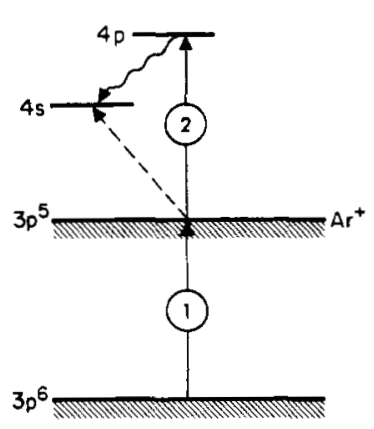

(a)



(b)

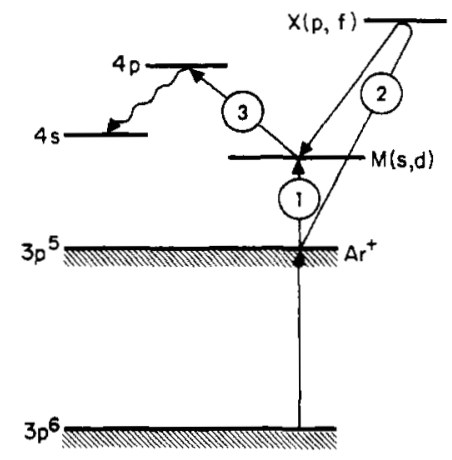

(c)

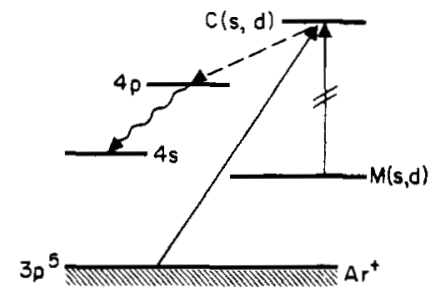

$3 p^{6}$

(d)

Fig. 3. Energy level diagrams for the blue and green transitions in Ar II, showing various excitation schemes (from [17]).

\section{B. Excitation Mechanisms of Ion Lasers}

The original model of laser excitation in noble gas ions was proposed by Gordon et al. [15], [16], and is shown schematically in Fig. 3(a). In Gordon's model, the upper laser level is excited by collisions between an electron and a ground state ion (process 2 ); the ion was presumably produced by the collision of an electron and a neutral atom in the ground state (process 1). Radiative cascade from higher states and de-excitation of the upper laser level by electrons are neglected. The lower laser level is rapidly depopulated by radiation (in the vacuum UV at $\lambda \approx 740 \AA$ for the $4 s$ states of Ar II). This depopulation is assumed to occur much more rapidly than any collisional electron excitation (dotted arrow). Finally, one assumes approximate charge neutrality in the plasma and current-independent electron temperature. Then the upper laser level population $\mathrm{N}_{2}$ turns out to vary as

$$
N_{2} \propto n_{e} n_{i} \approx n_{e}^{2} \propto J^{2}
$$

where $n_{e}, n_{i}$, and $J$ are the electron density, ion density, and discharge current density, respectively. Such a quadratic current dependence has been observed in spontaneous emission measurements over a wide range of gas pressures, currents, and tube dimensions typical of $\mathrm{CW}$ ion lasers (see, for example, [17] and [18]). However, in pulsed operation, radiation trapping of the lower level population can upset the simple current dependence of (1). (See Section III-C for a discussion of this effect.)

An alternate excitation method involving a single electron collision was proposed by Bennett et al. [3] and is shown in Fig. 3(b). This excitation process apparently occurs principally in low-pressure discharges excited by short pulses. A discharge with very high $E / p$ is required to produce an electron temperature sufficiently high to achieve a significant single step excitation rate. This mode of operation is also characterized by a unique distribution of spectral output. For example, under these conditions, $0.4765 \mu \mathrm{m}$ is the strongest laser line in Ar II. Such a spectral distribution is never observed in CW operation, where the $0.4880-\mu \mathrm{m}$ and $0.5145-\mu \mathrm{m}$ lines always dominate. Moreover, the single step excitation process (assuming constant electron temperature) would lead to a spontaneous emission rate from the upper laser level which varies linearly with discharge current, which is not observed in CW operation.
An additional excitation process was proposed by Labuda et al. [19], with ionic metastables serving as the intermediate species rather than the ion ground state, as shown in Fig. 3(c). Absorption measurements [19] show that these metastable levels are highly populated. The ionic metastables are produced either by electron collision with the ionic ground state [process 1 in Fig. 3(c)] or (more probably) by cascade from higher lying states (process 2); these higher lying states exhibit populations $N_{X} \propto J^{2}$, as shown by spontaneous emission data. However, because the metastables are primarily destroyed by electron collisions rather than by spontaneous emission, it can be shown that the metastable population $N_{m}$ will be proportional to $J$ rather than $J^{2}$ (see [16] or [17]). The upper laser level is then populated by yet another electron collision (process 3), and the relation $\mathrm{N}_{2}$ $\propto J^{2}$ obtains as before.

Our understanding of the upper level excitation processes remained essentially as described above until the measurements made by Rudko and Tang [20]. They found that a significant fraction of the upper laser level population was created by radiative cascade from higher lying states [see Fig. 3(d)]. By summing the spontaneous emission intensities of all spectral lines terminating on a given upper laser level (for example, $4 p^{2} D_{5 / 2}^{0}$, the upper level of the $0.4880-\mu \mathrm{m}$ transition), and then comparing this with the sum of intensities of those lines originating from that level, we may determine the relative pumping rate due to cascade from the higher lying states. In a 1-mm-diameter tube operated without a magnetic field, Rudko and Tang found that approximately 50 percent of the $4 p^{2} D_{5 / 2}^{0}$ level population is created by cascade. Similar measurements were made by Bridges and Halsted [17], who obtained a value of 23 percent for the cascade contribution to this same level in a 3mm-diameter tube operated without a magnetic field and 22 percent for the cascade contribution to the $4 p{ }^{4} D_{5 / 2}^{0}$ $(0.5145-\mu \mathrm{m})$ upper level. Since the populations $N_{c}$ from which the cascade takes place also exhibit a quadratic dependence on $J$, the same quadratic dependence $N_{2} \propto J^{2}$ results again. Note that the upper laser level population due to cascade cannot be separated from that due to two-electroncollision processes by its current dependence alone. It may be seen from the foregoing discussion that the characteristics of ion lasers are a direct consequence of the collision and radiation processes occurring within the ion laser plasma. 


\section{Fundamentals of the Ion Laser Plasma}

In this section we will present a brief physical description of the basic ion laser plasma, excluding spectroscopic properties. Many interesting problems such as gas pumping, throat erosion, etc., which are associated with ion lasers will be discussed later in Section III. Although such problems are all connected with the plasma properties, they are also dependent on the overall geometry; however, in this section we will treat the local discharge properties in the laser bore without regard to geometric properties other than tube radius. On this basis the ion laser discharge can be well characterized as given by the following independent parameters.

$R$ Tube radius, $\mathrm{cm}$.

$J$ Discharge current density, $\mathrm{A} / \mathrm{cm}^{2}$.

$p$ Externally measured gas pressure, torr.

$B$ Axial magnetic field, $\mathrm{G}$.

Ignoring spectroscopic quantities, such as level populations, the only macroscopic dependent property in this description is the axial electric field $E$, and various derived quantities (e.g., power input/length $=I E$ ). In addition, there are many microscopic properties such as species number density and temperature.

The remainder of this section is organized as follows. First, we will examine a particular ion laser discharge in some detail to establish the nature of the plasma under discussion. Second, we will review the experimental results obtained when the external conditions are changed (e.g., varying $J$ or $R$ ), including a brief discussion of the theoretical approaches that have been taken in attempting to explain these observations.

The particular example we will consider is a $2-\mathrm{mm}$ diameter smooth quartz capillary tube with a continuous dc discharge current of $5 \mathrm{~A}$. This is not typical of present-day ion lasers, which commonly operate at currents of 20-30 A or more in bores constructed of smooth wall ceramics, refractory metal disks, or graphite segments. However, there are several justifications for using this particular example. Most important is the availability of a reasonable body of data taken by R. C. Miller and coworkers at Bell Telephone Laboratories [21]. The low current chosen for these measurements was dictated by the use of quartz capillaries, which fail rather quickly at high currents. Also, although $5 \mathrm{~A}$ is not a state-of-the-art ion laser discharge, it is well over threshold for laser action, so that the plasma conditions are not atypical of ion laser discharges. Finally, comparisons among many ion laser devices, employing a wide variety of construction techniques ranging from solid dielectric wall capillaries to stacks of thin metal disks, have always demonstrated essentially identical laser and electrical performance for the same diameter discharge.

Although the available measurements limit our discussion primarily to the argon plasma, similar plasma properties are to be expected in krypton, xenon, and other ion laser species.

Table III summarizes the information known about the 2-mm-diameter 5-A argon discharge operating at an ex-
TABLE III

Selected Example of an Ion Laser Plasma

\begin{tabular}{ll}
\hline \hline Laser species & argon \\
Discharge tube diameter & $2 \mathrm{~mm}$ \\
Discharge current & $5 \mathrm{~A}$ \\
External pressure & $600 \mathrm{mtorr}$ \\
Electric field & $6.3 \mathrm{~V} / \mathrm{cm}$ \\
Current density & $160 \mathrm{~A} / \mathrm{cm}^{2}$ \\
Power dissipation & $31 \mathrm{~W} / \mathrm{cm}^{2}$ \\
Electron temperature (double probe) & $1.9 \mathrm{eV}\left(22000^{\circ} \mathrm{K}\right)$ \\
Ion temperature (Doppler width) & $0.17 \mathrm{eV}\left(2000^{\circ} \mathrm{K}\right)$ \\
Gas temperature (Doppler width) & $0.15 \mathrm{eV}\left(1700^{\circ} \mathrm{K}\right)$ \\
Electron density (stark broadening) & $3.4 \times 10^{13} \mathrm{~cm}^{-3}$ \\
Neutral density (X-ray absorption) & $5.8 \times 10^{15} \mathrm{~cm}^{-3}$ \\
Fractional ionization (calculated) & $0.64 \times 10^{-2}$ \\
Ion drift velocity (Doppler shift) & $1.2 \times 10^{4} \mathrm{~cm} / \mathrm{s}$ \\
Electron drift velocity (calculated) & $2.9 \times 10^{7} \mathrm{~cm} / \mathrm{s}$ \\
Plasma frequency & $52 \mathrm{GHz}$ \\
Debye shielding length & $1.8 \times 10^{-3} \mathrm{~mm}$ \\
Ion-atom mean free path & $0.2 \mathrm{~mm}$ \\
Electron-atom mean free path & $0.8 \mathrm{~mm}-12 \mathrm{~mm}$ (function of energy) \\
\end{tabular}

ternal pressure which yields maximum laser output. Several observations concerning the properties tabulated in Table III are in order.

1) The Debye length is $\sim 0.001$ times the tube diameter, which implies that charge neutrality is closely obeyed except in the sheath region near the wall.

2) The discharge, which is often referred to as an arc, is more closely related to a glow discharge despite the high power input. The large difference between gas and electron temperature illustrates this very clearly.

3) The plasma frequency is in a difficult measurement region. It is too high for RF or microwave measurements and too low for optical measurements. As a result, electron densities have been primarily measured by Stark broadening of the $\mathrm{H}_{\beta}$ line using small amounts of added hydrogen.

4) The plasma is dominated by boundary phenomena. Electron and ion mean free paths are comparable to the tube diameter. Ion loss is entirely to the walls and the mechanism controlling ion motion is intermediate between collisionless free-fall motion and ambipolar diffusion.

The combination of 1) boundary effects and 2) the lack of simplifying assumptions concerning particle motion is a fundamental cause of the present inadequate theoretical understanding of ion laser plasmas. We will return to this point after concluding our discussion of the experimental data.

Having established the nature of the ion laser plasma, we can now proceed to a discussion of the effect of varying discharge diameter, gas pressure, current density, and magnetic field. The amount of experimental information on CW ion laser plasmas is very small. Measurements by Kitaeva, Osipov, and Sobelev (KOS [22]) at the Physics Institute of the USSR Academy of Sciences, and by Miller, Labuda, and Webb (MLW [21]) at Bell Telephone Laboratories, provide the bulk of the available information. The data of KOS are based on spectroscopic measurements of longitudinal and transverse linewidths for various ion and neutral lines of argon. Two different bore diameters (2.8 and $1.6 \mathrm{~mm}$ ) were used, and measurements were made over a 
TABLE IV

Ion and Atom Temperatures as a Function of CURRENt Density

\begin{tabular}{cccccccc}
\hline & \multicolumn{3}{c}{$T_{i}\left({ }^{\circ} \mathrm{K}\right)$} & & \multicolumn{3}{c}{$T_{a}\left({ }^{\circ} \mathrm{K}\right)$} \\
\cline { 2 - 4 } \cline { 5 - 7 }$J\left(\mathrm{~A} / \mathrm{cm}^{2}\right)$ & $1.6 \mathrm{~mm}^{2}$ & $2 \mathrm{~mm}^{\mathrm{b}}$ & $2.8 \mathrm{~mm}^{\mathrm{c}}$ & & $1.6 \mathrm{~mm}^{\mathrm{a}}$ & $2 \mathrm{~mm}^{\mathrm{b}}$ & $2.8 \mathrm{~mm}^{\mathrm{c}}$ \\
\hline 160 & 2550 & 1800 & $3900^{\circ} \mathrm{K}$ & & 1250 & 1900 \\
200 & 2600 & & $4400^{\circ} \mathrm{K}$ & & 1700 & 1400 & 2300 \\
300 & 3800 & & $5600^{\circ} \mathrm{K}$ & & 1800 & 1600 & 3300 \\
400 & 3450 & & & & 2350 & & \\
500 & 4800 & & & 3000 & & \\
& & & & & & &
\end{tabular}

' V. F. Kitaeva, Yu. I. Osipov, and N. N. Sobolev, "Spectroscopic studies of gas discharges used for argon ion lasers," IEEE J. Quantum Electron., vol. QE-2, Sept. 1966, pp. 635-637.

${ }^{b}$ R. C. Miller and C. E. Webb, Bell Telephone Labs., Murray Hill, N. J., private communication.

c V. F. Kitaeva, Yu. I. Osipov, P. L. Rubin, and N. N. Sobolev, "On the inversion mechanism in the CW argon-ion laser," IEEE J. Quantum Electron., vol. QE-5, Feb. 1969, pp. 72-77.

range of current densities from 100 to $500 \mathrm{~A} / \mathrm{cm}^{2}$ and gas pressures from 100 to 700 mtorr. Measurements by MLW have utilized a variety of techniques, including spectroscopic measurements, double probes, and X-ray absorption. However, the range of current density investigated by MLW is somewhat restricted, so that intercomparison of data between the two investigators is difficult. We will not discuss pulsed ion laser plasmas as a separate category, even though some pulsed plasma measurements have been attempted [23]-[25], since sufficient data are not yet available.

Ion and Atom Temperatures: Ion and atom temperatures are deduced directly from Doppler linewidths and as a result are rather reliable. The data in Table IV, plotted against current density, are taken from both KOS and MLW. The consistency is relatively good, and Chester [26] has suggested the empirical formula

$$
T_{a} / 300=1+0.9 \times 10^{-2} J R^{1 / 2}
$$

for the atom temperature. Since data are available for tubes of small diameter only $(1.6,2.0,2.8,3.0 \mathrm{~mm})$ the validity of this formula has not been tested for large bore tubes. It is possible that the parameter $J R$ suggested by Herziger and Seelig [27] might provide an equally good fit over the wider range of bore diameters employed in modern ion lasers. The pressure dependence of the longitudinal ion temperature and the neutral temperature is small, no more than 10-20 percent for pressures from $0.15-5$ torr according to MLW. The transverse "temperature," or more correctly linewidth, is quite pressure dependent according to the measurements of KOS. The ion velocities transverse to the discharge are strongly affected by the electrostatic fields in the wall sheath. The observed Doppler linewidth results from a combination of random motion plus radial acceleration. This effect has been utilized by KOS to deduce electron temperatures for the ion laser plasma.

Electron Temperature: Direct electron temperature measurements utilizing a double probe have been made by MLW at low-current densities and at pressures somewhat above those commonly used in ion lasers. Their results indicate a slightly decreasing to constant electron tempera-
TABLE V

Electron Temperature and Density as a FunCtion of Current Density and Pressure

\begin{tabular}{cccccc}
\hline & & \multicolumn{5}{c}{$N_{e}\left(\mathrm{~cm}^{-3}\right) \times 10^{13}$} \\
\cline { 3 - 6 }$J\left(\mathrm{~A} / \mathrm{cm}^{2}\right)$ & $T_{e}$ & $\begin{array}{c}p=1.0 \\
\text { torr }\end{array}$ & $\begin{array}{c}p=0.62 \\
\text { torr }^{\mathrm{b}}\end{array}$ & $\begin{array}{c}p=0.37 \\
\text { torr }^{\mathrm{b}}\end{array}$ & $\begin{array}{c}p=0.21 \\
\text { torr }^{\mathrm{b}}\end{array}$ \\
\hline 50 & $27000^{\mathrm{a}}$ & 6.3 & & & \\
100 & $23000^{\mathrm{a}}$ & 4.3 & & & \\
150 & $37000^{\mathrm{b}}$ & 5.7 & 2.4 & 1.8 & 1.0 \\
200 & $50000^{\mathrm{b}}$ & 6.9 & 3.3 & 2.3 & 1.4 \\
250 & $60000^{\mathrm{b}}$ & 8.9 & 4.1 & 2.8 & 1.6 \\
300 & $70000^{\mathrm{b}}$ & & 4.6 & 3.1 & 1.8 \\
350 & $82000^{\mathrm{b}}$ & & 4.8 & 3.2 & 1.9 \\
\hline
\end{tabular}

- R. C. Miller and C. E. Webb, Bell Telephone Labs., Murray Hill, N. J., private communication. ( $T_{e}$ measured by double probe; $N_{e}$ measured by stark broadening. Tube diameter $2 \mathrm{~mm}$.) See also eq. (3.2) in [26].

b V. F. Kitaeva, Yu. I. Osipov, and N. N. Sobolev, Zh. Eksp. Teor. $F i$-., vol. 4, 1966, p. 213. ( $T_{e}$ deduced from $T_{i} ; N_{e}$ calculated from conductivity formula derived by V. N. Kolesnikov, doctoral dissertation, Physics Inst., USSR Academy of Sciences, 1962.

ture for $J<100 \mathrm{~A} / \mathrm{cm}^{2}$. Indirect measurements of electron temperature by KOS are based on the theory of Kagan and Perel' [28] which predicts the relation

$$
T_{i}=0.56 T_{a}+0.13 T_{e}
$$

between the effective transverse temperature $T_{i}$, the neutral gas temperature $T_{a}$, and the electron temperature $T_{e}$. They find an increase of $T_{e}$ proportional to $J$ up to the highest current density measured, $350 \mathrm{~A} / \mathrm{cm}^{2}$. They speculate that this linear dependence will continue to $550 \mathrm{~A} / \mathrm{cm}^{2}$ where the temperature would be $\simeq 11 \mathrm{eV}$. Although the ranges of measurement do not overlap, the result of these two investigations do not appear compatible. Further work on this subject is clearly needed.

It is clear that the electron temperature decreases with increasing pressure. The most rapid variation occurs in the range $0.1<p<1.0$. For pressures from 2 to 20 torr the electron temperature measured by MLW decreased by only 30 percent. Table $V$ summarizes the existing measurements of $T_{e}$ as a function of $J$ at a pressure of 0.5 torr.

Electron Density: The data of Table V concerning electron density are derived from measurements of MLW and from calculations of KOS based upon an electric conductivity formula derived by Kolesnikov [29]. It is clearly established by both investigators that the electron density at constant $J$ is approximately linearly proportional to the gas filling pressure. The calculations of KOS were checked by Stark broadening at one point $\left(p=0.4\right.$ torr, $\left.J=200 \mathrm{~A} / \mathrm{cm}^{2}\right)$ with nominal agreement, $2.3 \times 10^{13} \mathrm{~cm}^{-3}$ calculated and 3.4 $\times 10^{13} \mathrm{~cm}^{-3}$ measured. The calculation technique employed by KOS and by Herziger and Seelig [27] has been criticized by Lin and Chen [30] for neglecting the effect of electron "runaway" at high current densities. A decision as to whether the more complete theory of Lin and Chen offers a significant advantage over the simple scaling laws proposed by others will be possible only if considerably more experimental work becomes available, particularly for larger diameters and higher current densities. 
Neutral Atom Density: The neutral atom density is very difficult to measure in small capillary discharges. Absorption of X-rays passing along the length of the capillary was employed by MLW to deduce total atom + ion densities, but the results were reliable only at pressures greater than those employed in laser discharges. They observed a decrease in neutral atom density with increasing atom temperature as would be expected from simple gas law considerations. However, the measured densities were consistently 20-40 percent higher than those calculated from the gas law relation

$$
\frac{p}{p_{0}}=\frac{300}{T_{a}}
$$

This is not surprising considering the strong dynamic forces acting on the gas (see the discussion on gas pumping which follows) and the small conductance of the discharge tubes. Miller [31] has suggested that the theory of thermal transpiration might be more appropriate to this situation since the atomic mean free path is comparable to the tube radius for the smaller bore lasers. The gas law relation has not been tested experimentally in larger bore lasers where it is most likely valid. Nonetheless, it is used by most of those who advance theoretical explanations of ion laser plasmas. Both KOS and Herziger and Seelig [27] use it to obtain the neutral number density needed in the electric conductivity calculation, and Lin and Chen [30] have used a more complete form in which the external pressure is set equal to the total pressure of atoms, ions, and electrons.

Electric Field Gradient: The axial electric field measured under condition of optimum ${ }^{2}$ laser action $(p R \simeq 0.1$ torr $\cdot \mathrm{cm})[32]$ is observed to obey the relation [17], [26], [32]

$$
E_{z} R=6.5 \mathrm{~V}
$$

for $0.5<R<7.5 \mathrm{~mm}$. The dependence of $E_{z}$ on $J$ and $p$ is small for $J R<50 \mathrm{~A} / \mathrm{cm}$. Herziger and Seelig [32] find $E_{z} \propto J$ for $J R>200 \mathrm{~A} / \mathrm{cm}$. The laser discharge typically exhibits a small positive resistance except at low $J$ (usually below laser threshold) where a pronounced negative resistance is observed [26]. Again the gradient is very constant at cold filling pressures near and above optimum and begins to rise only when the fill pressure is reduced well below the optimum value.

Magnetic Field: The experimental results discussed up to this point have all been taken with no axial magnetic field; in actual fact, very few plasma data have been measured for ion laser plasmas in a magnetic field. This may seem somewhat surprising considering that almost all commercial CW ion lasers operate with a magnetic field to improve efficiency. Many investigators feel, however, that the magnetic field operates in a simple way to reduce ion loss by slowing down the electron transport to the walls, and that very little additional information will be learned about excitation mechanisms by studying the plasma in a magnetic fieid. This point of view is supported by measurements of

\footnotetext{
${ }^{2}$ Somewhat lower optimum pressures apply to the krypton and xenon ion laser plasmas.
}



Fig. 4. Variation of the intensity of the spontaneous endlight with axial magnetic field for a number of Ar II ion laser line and neutral Ar I lines (from [17])

laser output versus current which yield the same functional dependence with a magnetic field as without, except at proportionately lower discharge current. The effect of the magnetic field, however, is somewhat more complicated than this, as illustrated in Fig. 4. The spontaneous emission at constant current from ion lines is observed to increase 2.5 to 3 times with increasing magnetic field, while spontaneous emission from neutral atom lines is observed to decrease. The neutral level populations are saturated and their intensity is a function of electron temperature and not electron density (cf. [33]). The observed decrease in neutral line emission implies a decreasing electron temperature. The ion level populations are therefore determined by the interaction of ion density and electron temperature. The decrease in electron temperature is also borne out by an observed decrease in the axial electric field strength with increasing magnetic field [17].

There is an optimum value of magnetic field which depends primarily upon tube diameter. For a $1-\mathrm{mm}$-borediameter argon ion laser, a field of $1500 \mathrm{G}$ is typical, while for $8 \mathrm{~mm}$ the optimum is only $400-600 \mathrm{G}$. Values for krypton and xenon ion lasers are generally lower still. The results of Herziger and Seelig [32] indicate that the improvement gained with magnetic field is not significant for bore diameters $\geq 10 \mathrm{~mm}$.

Summarizing this section on plasma properties, we have seen that sufficient experimental evidence exists to establish clearly the nature of the ion laser plasma. If, however, the theory of ion laser performance is to proceed successfully to a satisfactory explanation of performance based on calculation of atomic excitation rates, from the empirical scaling law stage it occupies presently, then plasma measurements must be extended and refined to provide a more satisfactory foundation.

\section{Physics and Technology of Practical Ion Lasers}

We will now proceed to discuss a number of interesting and important effects that arise when this basic ion laser plasma is incorporated into a practical device. Some of these additional effects relate to device technology, and some represent physical processes that we have not yet discussed in sufficient detail. 


\section{A. Gas Pumping in Ion Lasers}

One of the interesting and practically important characteristics of the high-current-density low-gas-pressure ion laser discharge is the rapid pumping of gas from one end of the tube to the other. In the first $\mathrm{CW}$ ion lasers it was found that after tens of seconds of operation the filling gas would be pumped from the cathode and bore to the anode to such a degree that laser action would cease and the discharge would extinguish. A convenient solution to this problem is to provide some form of gas return path external to the discharge which connects the anode and cathode ends and allows an external equalizing flow of neutral gas to occur [10]. A gas return path having approximately the same diameter as the laser bore, but somewhat greater length to prevent electrical breakdown, is found to be adequate to achieve maximum laser output and adequate discharge stability.

Even with a high-conductance external gas return path, very large anode to cathode pressure differentials may still occur. Fig. 5 shows the measured anode to cathode pressure differential $\Delta p$ as a function of discharge current for a number of different values of gas filling pressure. These data were taken on a quartz tube filled with argon, having a 3-mm-diameter by $46-\mathrm{cm}$-long bore [17]. At $25 \mathrm{~A}$ and the optimum gas fill of 0.25 torr and magnetic field of $1.05 \mathrm{kG}$, this tube produced a laser output of $3 \mathrm{~W}$. The notation $C_{B}=C_{E}$ indicates that the calculated gas conductance of the external gas return path was equal to that of the bore when the gas in both was at room temperature. Similar pressure differentials and current dependence were measured in tubes of different diameters, and filled with krypton or xenon [17].

The pressure differential $\Delta p$ is observed to be strongly dependent on the gas pressure and discharge current. At 3 torr, the pressure differential increases linearly up to about $5 \mathrm{~A}$, and then saturates. All previous experimental studies of gas pumping reported in the literature [34]-[36] were made at low discharge currents $(<1 \mathrm{~A})$. Accordingly, only the initial linear increase of $\Delta p$ with current predicted by theory was observed.

At the low gas pressures that are optimum for laser action ( 0.16 to 0.25 torr in a 3-mm tube), $\Delta p$ first increases and then decreases sharply with increasing current, and actually can become negative as shown in Fig. 5. Previous to these measurements on ion lasers, no such behavior had been reported. The magnitude of $\Delta p$ should be noted ; in a typical laser, $\Delta p$ across the bore can be as great or greater than the initial fill pressure, depending on the discharge current, pressure, and size of the gas volumes attached at anode and cathode ends.

It is extremely important that anyone performing measurements on ion lasers appreciate the strong dependence of pumping rate and $\Delta p$ on discharge current, magnetic field, and filling pressure. Often measurements of line intensities, electron temperature, plasma density, etc., as a function of $I, B$, or $p$ are taken at a fixed position along the bore. Obviously such measurements will be strongly affected by changes in the neutral gas density caused by gas



Fig. 5. Anode-to-cathode pressure differential versus discharge current in a typical argon ion laser discharge for different values of gas filling pressure (from [17]).

pumping. The characteristics measured at different positions along the bore can exhibit markedly different dependences because of gas pumping effects. The practical importance of gas pumping effects in ion lasers has prompted new theoretical analysis which has extended the early treatments of Langmuir [37] and Druyvesteyn [38]. Halsted [17] and, in a more thorough analysis, Chester [26], [39] have analyzed gas pumping in the gas pressure range of interest in ion lasers, including in their analyses provisions for an external gas return path.

A general explanation of the cause of gas pumping can be given qualitatively as follows. While ions and electrons within the positive column gain equal but opposite momentum from the axial electric field, greater momentum is delivered by the electrons to the neutral gas than by the ions, or equivalently, greater momentum is transferred to the walls by the ions than by the electrons. This difference can be analyzed by consideration of the differing longitudinal and axial drift rates, mean free paths, and recombination rates [40] of the two species. A detailed discussion of these effects is contained in [39]. Suffice it to say here that recent theory gives an accurate explanation of the pressure differences experimentally observed in ion lasers.

A basic appreciation of the factors influencing gas pumping in ion lasers may be obtained by considering the schematic representation of the laser bore and external return path shown in Fig. 6. Acting within the bore of the tube we have two pumping sources $Q_{\text {pump }}$ and $Q_{\text {ion }}$. From these two sources a pressure differential $\Delta p$ develops which causes a gas flow through the vacuum conductances of the external gas return tube $C_{E}$ and the bore $C_{B}$. Physically, $Q_{\text {ion }}$ results from the axial drift of ions in the positive column. Since these ions become neutral atoms at the cathode, this ion flow is equivalent to an equal amount of gas flow. The source $Q_{\text {pump }}$, as referred to above, is less obvious physically and results from the net transfer of mo- 


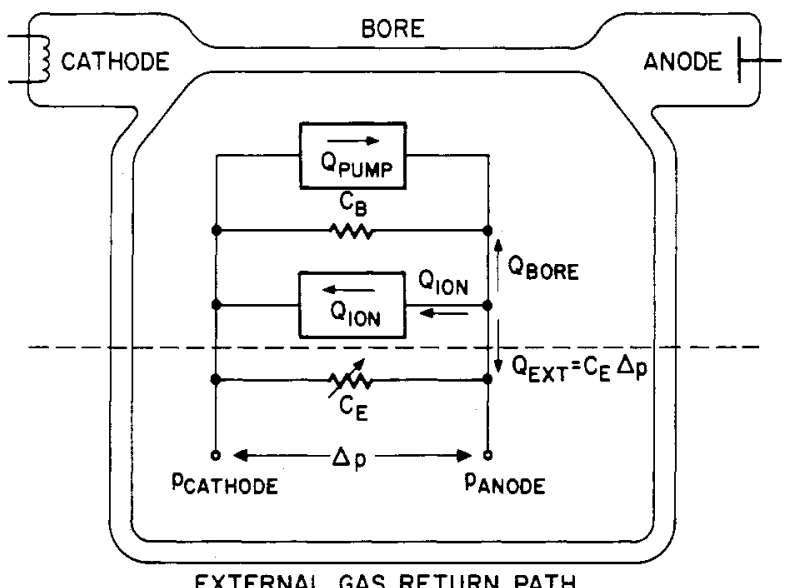

EXTERNAL GAS RETURN PATH

Fig. 6. Schematic representation of the laser discharge tube showing the forces acting on the gas, and the bore and external gas return path conductances.

mentum to the gas by electrons, and thus is always anode directed. Note that if $Q_{\text {pump }}$ just equals $Q_{\text {ion }}, \Delta p$ across the tube will be zero. Under these conditions, there must still be a flow of neutral gas toward the anode equal to $Q_{\text {ion }}$. This flow is driven by net electron collisions with neutrals even in the absence of a neutral pressure gradient. When $Q_{\text {pump }}$ is greater than $Q_{\text {ion }}$, the anode pressure will increase until $\Delta p$ is sufficient to cause an anode-to-cathode flow through the bore and external return path equal to $Q_{\text {pump }}-Q_{\text {ion }}$.

As reflected in the schematic diagram, $\Delta p$ is found to vary inversely with the quantity $\left(C_{E}+C_{B}\right)$. This relationship is verified experimentally [17], provided one accounts for the strong dependence of the gas conductance of the bore on the temperature of the neutral gas. The high temperature of the gas in the bore (typically $>1000^{\circ} \mathrm{C}$ at the higher discharge currents of practical interest) is the cause for the decrease in $\Delta p$ with increasing discharge current shown in Fig. 5. This occurs both because of the decrease in gas number density in the bore, which reduces the pumping force, and because of an increase in the viscosity of the gas, which reduces the effectiveness of the pumping force in moving gas from cathode to anode.

The strong dependence of gas conductance on neutral gas temperature has an important role in the design of tubes having internal rather than external gas return paths. It may be shown that for viscous flow the conductance varies as the $7 / 4$ power of the gas temperature. Thus the conductance of a path containing gas at $1000^{\circ} \mathrm{C}$ is only $1 / 13$ of its value at room temperature. The trend in compact tube design is to try to include the gas return path within the bore structure to avoid the awkwardness and fragility of an external by pass tube such as that described in [10]. In tubes using radiation-cooled metal or graphite disks [17], [18], designers often attempt to employ off-axis holes in the segments as a gas return path. Because the gas passing through these segments is hot, typically $1000^{\circ} \mathrm{C}$, these paths are not nearly as effective in reducing the pressure differential in the bore as an external path at room temperature, with the result that very large cross-sectional areas must be devoted to gas flow in such tubes if adequate off-axis flow is to be provided.

Ion laser tubes of advanced design (cf. Fig. 1) now use off-axis holes within a solid conduction-cooled beryllia bore to provide a gas return path. The gas in these off-axis paths is at the wall temperature of approximately $100^{\circ} \mathrm{C}$, and hence provision for adequate gas return path conductance is easily made.

\section{B. Conditions at Laser Bore Constrictions}

Physical damage to the inside of the walls confining the discharge, primarily in the vicinity of the cathode-end throat or bore constriction, often limits the maximum laser input power. In glass or quartz tubes, discoloration and erosion are observed in this region and in metal segment or disk-bore tubes, severe heating and sputtering damage is noted. Quantitative data showing an example of localized power dissipation are presented in Fig. 7. The bore of the tube shown was constructed using the common ion laser technique of electrically isolated radiation-cooled bore segments, supported in a quartz vacuum envelope, to confine the discharge. Information on conditions in the throat may be deduced from measurements of the temperature of the radiation-cooled segments. The bore segments in Fig. 7 are drawn to scale so that the temperature reading of a particular segment is plotted directly below the segment. Segment 8 , the last tapered segment in the throat, operated at the highest temperature. At $1200^{\circ} \mathrm{C}$, this segment radiates (and therefore absorbs from the discharge) more than double this power of a segment at $1050^{\circ} \mathrm{C}$. From such measurements as these, one may conclude that localized power dissipation is more severe the more abrupt the throat transition, and that power dissipation is also a strong function of the position of the throat relative to the converging axial magnetic field (cf. [17]).

The conditions of localized heating occur in the throat because of the existence of a double sheath which forms to equalize the random plasma electron currents passing between the large and the small diameter regions of the bore. A general model of conditions in the vicinity of a discharge constriction has been described by Langmuir [41] and others [42]. To understand why a sheath must form, consider that the large and small diameter regions at the constriction are characterized by electron densities and temperatures $n_{e}$ and $T_{e}$. The random electron current in each region is therefore proportional to $n_{e} T_{e}^{1 / 2}$. Since the electron density and temperature are greater in the small diameter region than in the large, the random electron currents must be greater in the small bore region. Across the constriction, the net electron current flow must be equal (ignoring for the moment the directed discharge current), and therefore a sheath of potential $V_{s}$ must form at the constriction to reduce the greater outward flow of electrons from the small bore, as shown in Fig. 8. If the directed discharge current is accounted for, the effect is to increase the sheath height at the cathode-end bore constriction and to reduce the sheath height at the anode end. 


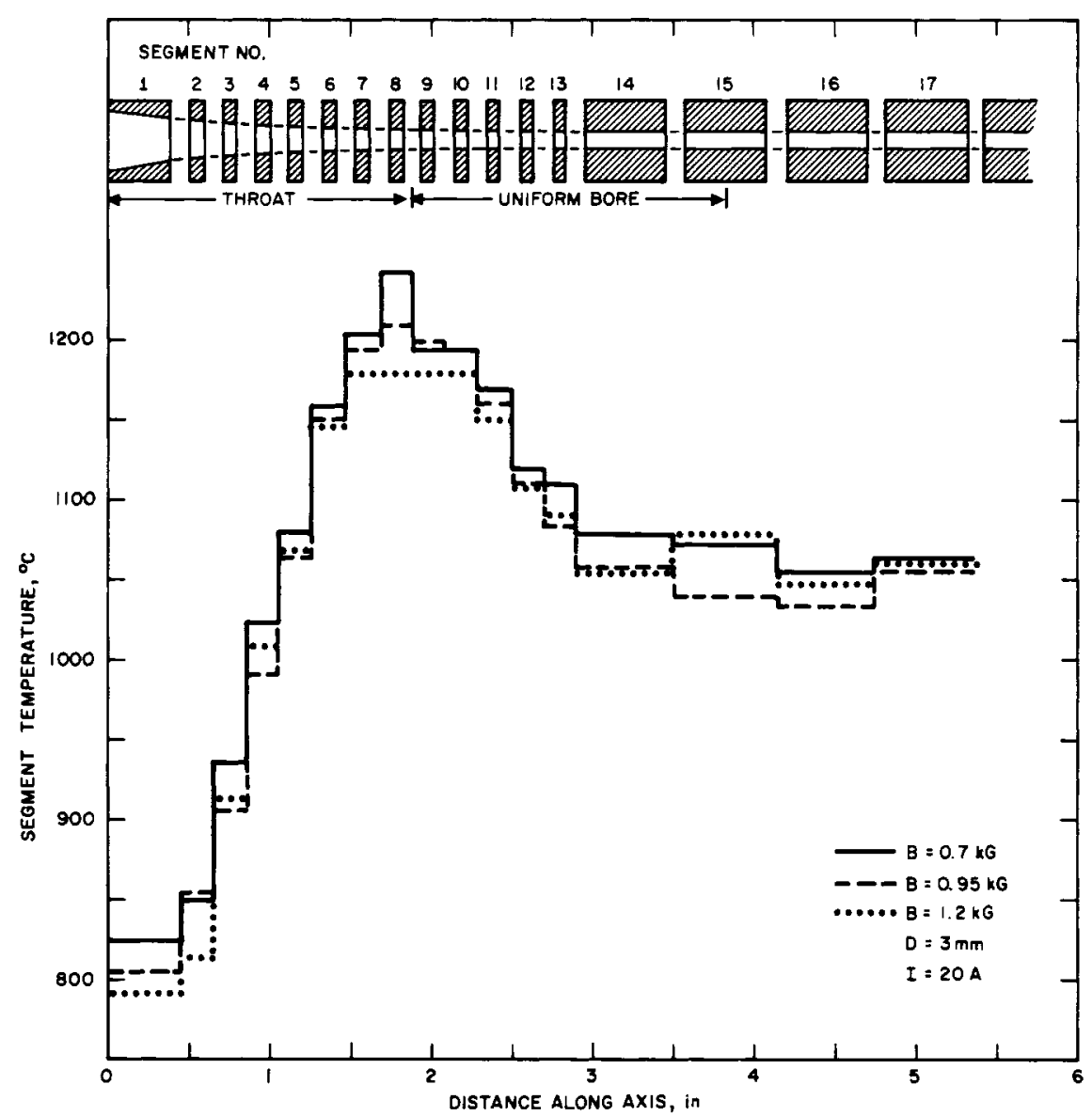

Fig. 7. Variations of the temperature along the bore of a radiation-cooled segmented graphite bore ion laser, showing the dependence on the electric field strength in the throat region. Bore segments are drawn to scale at the top of the figure (from [43]).

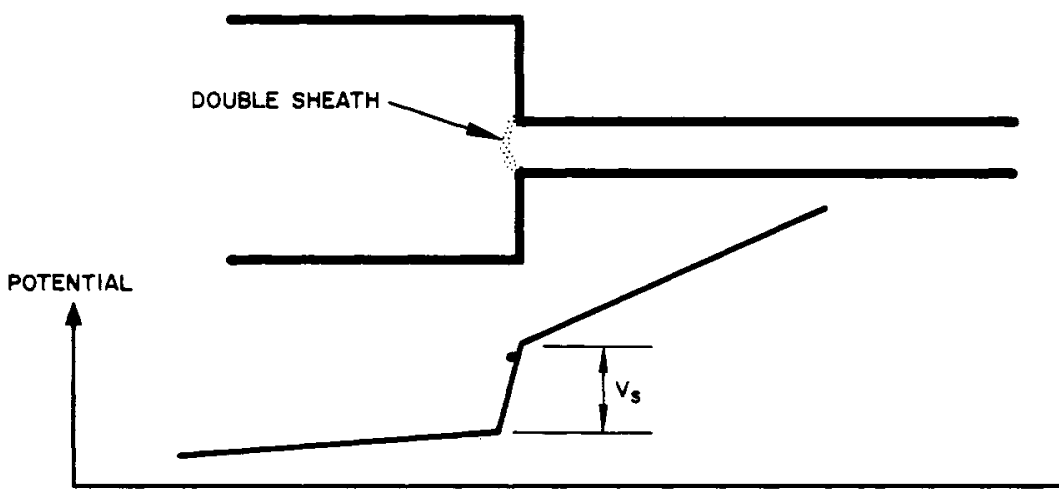

\section{ELECTRIC FIELD}

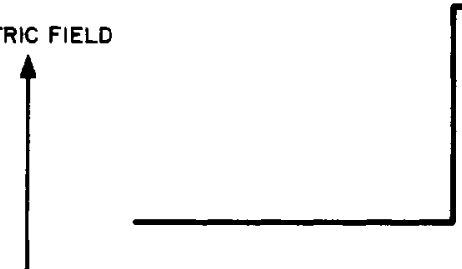

Fig. 8. Schematic representation of the potential and the electric field distributions in the vicinity of an abrupt discharge constriction. 

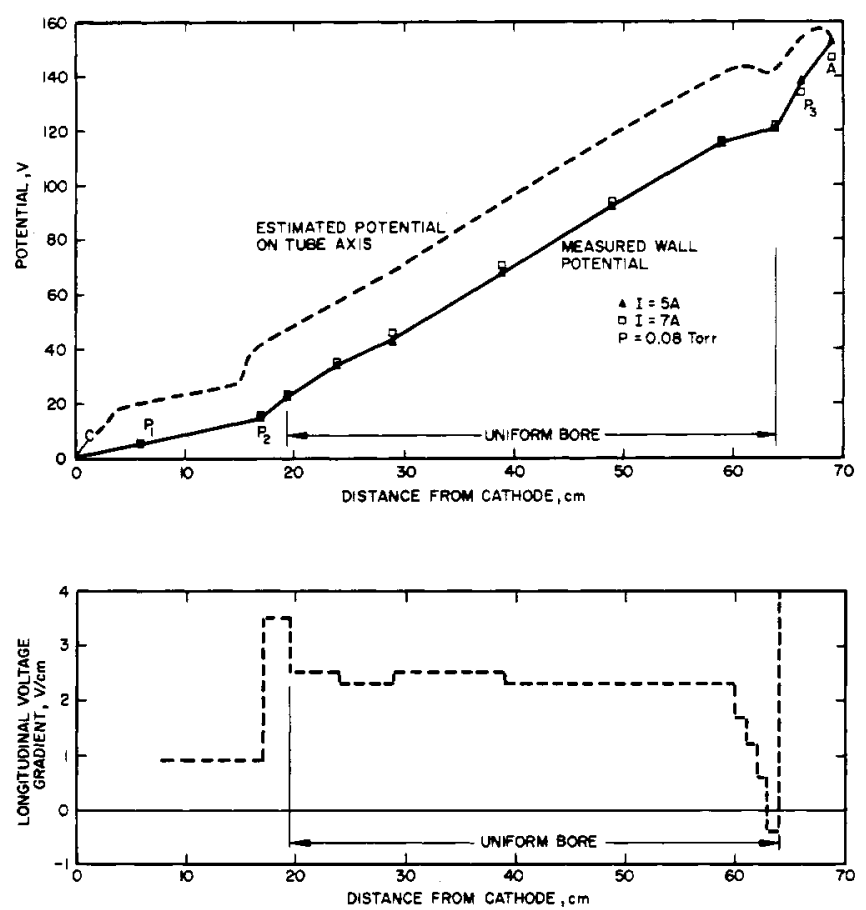

Fig. 9. Wall potential (upper curve) and longitudinal potential gradient (lower curve) as a function of distance along the discharge column of an air-cooled quartz discharge tube (from [17]).

We have directly measured the variation in wall potential and potential gradient in an air-cooled quartz bore laser using a combination of fixed and movable wall probes and a high-impedance voltmeter. The measured variation in wall potential and voltage gradient along the wall is shown in Fig. 9, and the potential on axis is sketched assuming appropriate values for electron temperature in the large and small diameter regions. The measured variation in potential and electric field is in good agreement with the behavior predicted by the simple model. The sheath heights at the cathode and anode constrictions were approximately +10 $\mathrm{V}$ and $-4 \mathrm{~V}$, respectively, being increased and reduced slightly by the directed discharge current, and, as expected, were independent of current to first order. Because of the presence of the double sheath, electrons will be accelerated through the sheath from the cathode region and will raise the electron energy, ionization rate, and wall sheath height in the throat region. This is believed to account for the increased heat dissipation and sputtering damage in the throat region.

In low-pressure mercury glow discharges, it has been claimed that double sheaths of the type described above produce very strong low-frequency oscillations, presumed to be ion waves [42]. Under certain discharge conditions we have observed laser modulation at discrete frequencies in the range of 150 to $220 \mathrm{kHz}$ [43]. This modulation also appears as modulation of the spontaneous sidelight emission. It has been determined that this modulation is strong in the cathode and cathode throat regions of the discharge, but not in the uniform bore. This suggests that the modulation may be due to waves excited by oscillations excited in the double sheath as reported in [42]. However, this must remain as speculation pending further experiments.

The exact choice of shape for the bore constrictions at the anode and cathode has been largely determined by empirical design. Especially at high discharge current densities, and in CW krypton and xenon ion lasers which are subject to discharge instabilities, the design of the throat can very much affect the maximum current and power output that can be obtained. A fuller discussion will be found in [17] and [43].

\section{Radiation Trapping}

Another interesting phenomenon that plays a role in typical ion laser plasmas is the trapping or reabsorption of spontaneously emitted radiation. We mentioned earlier that the lower laser levels (the $4 s$ levels shown in Fig. 2 , in the case of the Ar II laser) are populated by electron collision, by spontaneous cascade from higher levels, and by the laser transition itself. Despite these populating processes, an inversion between upper and lower laser levels can be maintained because the lower level has a very rapid radiative decay to the ion ground state in the vacuum ultraviolet $(723 \AA$ for the Ar II $4 s^{2} P_{3 / 2} \rightarrow 3 p^{5}{ }^{2} P_{3 / 2}$ transition). The ratio of $A$ coefficients for this process to the laser $A$ coefficients is typically large:

$$
\frac{A_{723}}{A_{4880}}=26, \quad \frac{A_{723}}{A_{5145}}=325
$$

as calculated by Statz et al. [44, with corrections].

However, radiation trapping can reduce the effective decay rate and increase the lower level population. The 723- $\AA$ photons are absorbed by ground state ions before they can escape from the plasma, thus creating new $4 s^{2} P_{3 / 2}$ excited lower levels. These, in turn, reradiate, and so forth. The net effect is that the lower level is depopulated by a diffusion of radiation to the edge of the plasma rather than by direct radiation to the outside world. The theory of this mode of radiation transport is well known from the classical work of Holstein [45], [46]. It is difficult to apply Holstein's theory quantitatively because of uncertainties in the ion laser plasma parameters. Reasonably good qualitative agreement can be obtained for some of the more pronounced phenomena, however.

One prominent feature of pulsed ion lasers that results from radiation trapping is the occurrence of a "dead," or negative gain interval near the beginning of the light output pulse. This dead region develops gradually with increasing current, as shown in Fig. 10. The top trace shows the $0.488-\mu \mathrm{m}$ laser output as a function of time for a $16.7-\mathrm{A}$ current pulse. The corresponding current pulse is not shown in Fig. 10, but it begins at $t=0$, rises to its peak value by $t=10 \mu \mathrm{s}$, remains essentially flat to $t=40 \mu \mathrm{s}$, and then drops to zero at $t=55 \mu \mathrm{s}$. For the small value of peak current used in the top trace, $8 \mu$ s of the $10-\mu$ s rise time is needed to reach oscillation threshold. As the peak current is increased to $25 \mathrm{~A}$, this initial delay is decreased, and a slight dip in the output develops at about $t=10 \mu \mathrm{s}$. With a peak current of 33.3 A (third trace from the top) the dip is more pronounced, almost reaching zero output at $t=10 \mu \mathrm{s}$. At still higher currents, the output pulse has separated into two discrete parts with a zero output region in between. Transmission mea- 


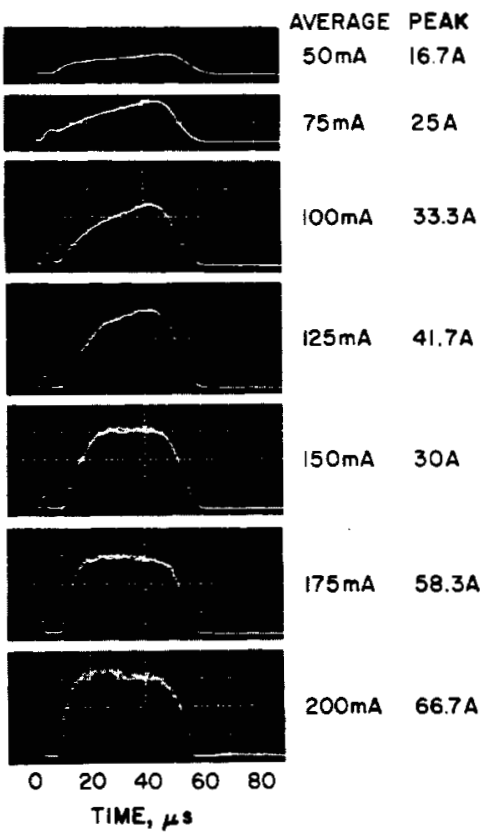

Fig. 10. Time variation of the $0.4880-\mu \mathrm{m}$ Ar II output in a small pulsed ion laser ( $2-\mathrm{mm}$ diameter by $30 \mathrm{~cm}$ ) as the peak discharge current is increased.

surements by a number of workers [6], [23], [47], [48] have confirmed that this dead period is actually absorbing, that is, the lower laser level is temporarily more highly populated than the upper level.

A similar evolution of a dead period can take place if the peak discharge current is fixed and the gas pressure is increased. In this case, the width of the dead period increases in both directions in time until the entire output pulse is "swallowed up." Likewise, at appropriately adjusted current and pressure, a similar sequence of time variations can be seen as a function of radial position in the discharge. The output near the discharge wall shows no dead region, while a progressively wider dead region develops toward the tube axis. It is possible to adjust current and pressure so that the laser oscillates only near the tube walls, producing ring-like output modes as reported by Cheo and Cooper [49], provided the laser cavity will allow such high-order transverse modes.

All these characteristics were recognized early in the history of ion lasers; the temporal and spatial variations were mentioned in the initial paper on the argon ion laser $[1]^{3}$ The first explanation of these observations in terms of radiation trapping was given by E. I. Gordon (private communication) in June, 1964. This argument has been further confirmed for a pulsed laser by Klein [23], and may be summarized briefly as follows (see [17] or [23] for more detailed developments). According to Holstein, the effect of radiation trapping may be expressed by modifying the total $A$ coefficient of the radiating level (in this case the lower laser level $N_{1}$ ) by a trapping factor $\gamma$ so that $A_{1}$ is replaced by $\gamma A_{1}$.

The gain coefficient of an ion laser can then be written

\footnotetext{
${ }^{3}$ The reference to this phenomenon in the text of $[1, p .130]$ sounds a little strange, however, since the accompanying oscilloscope trace was deleted in the interest of a shorter paper.
}

$$
g_{0}=K_{1} J^{2}\left(1-\frac{K_{2}}{\gamma}\right)
$$

where $K_{1}$ and $K_{2}$ involve only atomic constants (Einstein coefficients, excitation cross sections, wavelength, etc.) independent of $J$. A two-step excitation process has been assumed in (7), giving a $J^{2}$ dependence of gain. For a cylindrical discharge configuration, Holstein gives the trapping factor as

$$
\gamma=\frac{1.60}{k_{0} R\left[\pi \ln \left(k_{0} R\right)\right]^{1 / 2}}
$$

where $k_{0}$ is the absorption coefficient of the trapped line and $R$ is the discharge radius. If we ignore the slowly varying logarithmic term and note that $k_{0} \sim n_{i} / \Delta v_{d}$, where $n_{i}$ is the ion ground state density and $\Delta v_{d}$ is the Doppler linewidth of the absorbing vacuum UV transition, then

$$
\gamma \sim \frac{\Delta v_{d}}{n_{i} R}
$$

Moreover, if $n_{i} \sim n_{e} \sim p J R$ (cf. [21] quoted in [26]) for the plasma region of interest here, then

$$
g_{0}=K_{1} J^{2}\left(1-\frac{K_{3} p J R^{2}}{\Delta v_{d}}\right)
$$

where $K_{3}$ absorbs the remaining constants all assumed to be relatively insensitive to $p, J, R$, and $\Delta v_{d}$.

Equation (10) now indicates what happens as the pulse current builds up: the gain rises as $J^{2}$ until the second term in parentheses becomes significant. When $J$ is large enough to make this term unity, the gain drops to zero and then becomes negative (absorption) on further increase in $J$. However, the Doppler linewidth also increases as the discharge heats up, a process that lags the time variation of $J$ to some extent. When the ion temperature is sufficiently high so that the increase in $\Delta v_{d}$ reduces this term below unity, the laser gain goes positive and oscillation returns. Increasing either the tube pressure or the tube radius makes the term larger in magnitude and lengthens the time required.

It is also clear from (10) that it is possible to increase $p$ or $R$ sufficiently so that no increase in $\Delta v_{d}$ will suffice, and this also has been observed. Klein [23] has measured the time development of the vacuum UV transition and $\Delta v_{d}$, simultaneously with the laser output from a pulsed Ar II laser, and is able to confirm these processes qualitatively.

The argument given has said nothing explicitly about the variation of radiation trapping with magnetic field. We would expect from the discussion in Section II that the addition of a magnetic field would be equivalent to an increase in $J$ without an increase in ion temperature. Thus the magnetic field should add to the power output when the $J^{2}$ variation dominates but detract from the laser output where trapping has become significant. Gorog and Spong [50] have investigated the output power and mode patterns as a function of both $B$ and $p$. Their results are also consistent with (10). Increasing either $B$ or $p$ sufficiently caused the formation of ring modes and a drop in laser power, but over a reasonable range of values, an increase in $B$ could be compensated by a decrease in $p$ or $J$ and vice versa. 
Despite the qualitative agreement with this simple picture of radiation trapping, there is clearly much more to be learned before truly quantitative predictions can be made. The problem of ionization to higher states has been raised by Cottrell [5] and these complicate any simple picture. Dealing with the problems of highly ionized species will be necessary to explain the behavior of the strong Xe IV lines, for example. It is possible that radiation trapping of several cascading processes will have to be treated.

\section{SUMMARY}

We have attempted to introduce the reader to the basic properties of ion laser plasmas and to relate these properties to the mechanisms responsible for the principal laser characteristics. Necessarily, we have had to omit many topics of interest to those engaged directly in ion laser research and development. For example, we have not gone into the details of discharge tube construction, including the choice of materials and configurations. Even though such details play important roles in obtaining reliable long-life laser operation, they do not affect the first-order plasma properties. Further details on a variety of construction techniques and technical properties are contained in [16]-[18], [43], and [51], among others. For a general review of CW argon ion lasers and a guide to the literature, we suggest the excellent paper by Kitaeva, Odintsov, and Sobolev [52].

\section{REFERENCES}

[1] W. B. Bridges, "Laser oscillation in singly ionized argon in the visible spectrum," Appl. Phys. Lett., vol. 4, April 1, 1964, pp. 128-130.

[2] G. Convert, M. Armand, and P. Martinot-Lagarde, "Effet laser dans der mélanges mercure-gaz rares," $C . R$. Acad. Sci., vol. 258, Mar. 23, 1964 , pp. 3259-3260.

[3] W. R. Bennett, Jr., J. W. Knutson, Jr., G. N. Mercer, and J. L. Detch, "Super-radiance, excitation mechanisms, and quasi-cw oscillation in the visible $\mathrm{Ar}^{+}$laser," Appl. Phys. Lett., vol. 4, May 15, 1964, pp. 180-182.

[4] V. V. Lebedeva, A. I. Odintsov, and V. M. Salimov, "Excitation conditions in argon ion lasers," Radio Eng. Electron Phys., vol. 13, Apr. 1968 , pp. $655-658$.

[5] T. H. E. Cottrell, "Output power characteristics of the pulsed argon ion laser," IEEE J. Quantum Electron., vol. QE-4, July 1968, pp. 435-441.

[6] S. M. Jarrett and G. C. Barker, "Direct gain measurements of pulsed argon-ion lasers," J. Appl. Phys., vol. 39, Sept. 1968, pp. 4845-4846.

[7] M. D. Sayers, "Single pass gain as a function of discharge current for the $4880 \AA$ argon ion laser," Phys. Lett., vol. 29A, Aug. 11, 1969, pp. 591-592.

[8] W. B. Bridges and A. N. Chester, "Spectroscopy of ion lasers," IEEE J. Quantum Electron., vol. QE-1, May 1965, pp. 66-84.

[9] - "Ion lasers," in Laser Handbook. Cleveland, Ohio: Chemical Rubber Publishing Co., to be published. For the most complete listing published to date, see [8].

[10] E. I. Gordon and E. F. Labuda, "Gas pumping in continuously operated ion lasers," Bell Sys. Tech. J., vol. 43, July 1964, pp. $1827-1829$.

[11] J. P. Goldsborough, "Stable, long life cw excitation of heliumcadmium lasers by de cataphoresis," Appl. Phys. Lett., vol. 15, Sept. 15, 1969, pp. 159-161.

[12] H. Boersch, J. Boscher, D. Hoder, and G. Schäfer, "Saturation of laser power of $\mathrm{cw}$ ion laser with large bored tubes and high power cw uv," Phys. Lett., vol. 31 A, Feb. 23, 1970, pp. 188-189.

[13] J. R. Fendley, Jr., "100-watt CW argon laser" (Unclassified), Proc. 4th DOD Conf. Laser Technology (San Diego, Calif., Jan. 1970), vol. 1, pp. 391-398 (unpublished).

[14] For a discussion of mode selection in lasers see for example $H$. Kogelnik, "Modes in optical resonators," in Lasers, vol. 1, A. K. Levine, Ed. New York: Marcel Dekker, Inc., 1966, pp. 295-347 (esp. pp. 330-333).
[15] R. C. Miller, E. F. Labuda, and E. I. Gordon, presented at the 1964 Conf. Electron Device Research, Cornell Univ., Ithaca, N. Y.

[16] E. F. Labuda, E. I. Gordon, and R. C. Miller, "Continuous-duty argon ion lasers," IEEE J. Quantum Electron., vol. QE-1, Sept. 1965, pp. $273-279$.

[17] W. B. Bridges and A. S. Halsted, "Gaseous ion laser research," Hughes Res. Labs., Malibu, Calif., Tech. Rep. AFAL-TR-67-89, May 1967 (unpublished); DDC accession no. AD-814-897.

[18] W. B. Bridges and G. N. Mercer, "Ultraviolet ion lasers," Hughes Res. Labs., Malibu, Calif., Tech. Rep. ECOM-0229-F, Oct. 1969; DDC accession no. AD-861-927.

[19] E. F. Labuda, C. E. Webb, R. C. Miller, and E. I. Gordon, "A study of capillary discharges in noble gases at high current densities," presented at the 1965 18th Gaseous Electronics Conf., Minneapolis, Minn.

[20] R. I. Rudko and C. L. Tang, "Excitation mechanisms in the Ar II laser," Appl. Phys. Lett., vol. 9, July 1, 1966, pp. 41-44.

[21] R. C. Miller, E. F. Labuda, and C. E. Webb, unpublished data 1964 1967, private communication.

[22] V. F. Kitaeva, Yu. I. Osipov, and N. N. Sobolev, "Electron temperature in the electric discharge used for the argon ion laser," JETP Lett., vol. 4, Sept. 15, 1966, pp. 146-148.

[23] M. B. Klein, "Radiation trapping processes in the pulsed ion laser," $\mathrm{Ph} . \mathrm{D}$. dissertation, Univ. of California, Berkeley, Mar. 1969 (unpublished).

[24] — "Time-resolved temperature measurements in the pulsed argon ion laser," Appl. Phys. Lett., vol. 17, July 1, 1970, pp. 29-32.

[25] S. Hattori and T. Goto, "Excitation mechanism and plasma parameters in pulsed argon-ion lasers," IEEE J. Quantum Electron., vol. QE-5, Nov. 1969, pp. 531-538.

[26] A. N. Chester, "Experimental measurements of gas pumping in an argon discharge," Phys. Rev., vol. 169, May 5, 1968, pp. 184-193.

[27] G. Herziger and W. Seelig, "Berechnung der Besetzungsdichte und Ausgangsleistung von Ionenlasern," $Z$. Phys., vol. 215, 1968, pp. $437-465$.

[28] Yu. M. Kagan and V. I. Perel, "On motion of ions and shape of their lines in the positive column of discharge," pt. 1, Opt. Spektrosk., vol. 2 , no. 3, 1957, p. 298.

- "Radial motion of ions in the low pressure discharge," pt. 2 , ibid., vol. 4, no. 1, 1958, p. 3

[29] V. N. Kolesnikov, "The arc discharge in inert gases," Ph.D. dissertation, 1963. Published in Proc. (Trudy) of the P. N. Lebedev Physics Institute, vol. 30, Physical Optics. New York: Consultants Bureau, 1966.

[30] S. C. Lin and C. C. Chen, "Kinetic processes in noble gas ion lasers, a review," presented at the AIAA 8th Aerospace Sciences Meeting, New York, Jan. 1970, Paper 70-82.

[31] R. C. Miller, private communication. See also discussion following (2.19) in [39].

[32] G. Herziger and W. Seelig, "Ionenlaser hoher Leistung," Z. Phys., vol. 219 , pp. 5-31, 1969.

[33] C. E. Webb, "Ion laser-Part 1: The radial distribution of excited atoms and ions in a capillary discharge in argon," in Proc. Symp. Modern Optics (New York, Mar. 1967).

[34] A. Ruttenauer, "Quantitative Bestimmung der Druckdifferenzen in der positiven Säule der Edelgase Argon-Neon und Helium," $Z$. Phys., vol. 10,1922 , pp. 269-274.

[35] C. Kenty, "Clean-up and pressure effects in low pressure mercury vapor discharges: A reversible electrical clean-up of mercury," J. Appl. Phys., vol. 9, Dec. 1938, pp. 765-777.

[36] R. B. Cairns and K. G. Emeleus, "The longitudinal pressure gradient in discharge tubes," Proc. Phys. Soc. (London), vol. 71, Apr. 1958, pp. 694-698.

[37] 1. Langmuir, "The pressure effect and other phenomena in gaseous discharges," J. Franklin Inst., vol. 196, Dec. 1923, pp. 751-762. See also The Collected Works of Irving Langmuir, vol. 4. New York: Pergamon, 1961.

[38] M. J. Druyvesteyn, "The electrophoresis in the positive column of a gas discharge," Physica, vol. 2, 1935, pp. 255-266.

[39] A. N. Chester, "Gas pumping in discharge tubes," Phys. Rev., vol. 169, May 5, 1968, pp. 172-184.

[40] C. C. Leiby, Jr., and H. J. Oskam, "Volume forces in plasmas," Phys. Fluids, vol. 10, Sept. 1967, pp. 1992-1996.

[41] I. Langmuir, op. cit., p. 751.

[42] F. W. Crawford and I. L. Freeston, "The double sheath at a discharge constriction," Stanford Univ., Stanford, Calif., Microwave Lab. Rep. 1043, June 1963 (unpublished).

[43] A. S. Halsted, W. B. Bridges, and G. N. Mercer, "Gaseous ion laser 
research," Hughes Res. Lab., Malibu, Calif., Tech. Rep. AFAL-TR68-227, July 1968; DDC accession no. AD-841-834.

[44] H. Statz, F. D. Horrigan, and S. H. Koozekanani, "Transition probabilities for some Ar II laser lines,' J. Appl. Phys., vol. 36, July 1965, pp. 2278-2286. The values for transitions to the ground state are underestimated by a factor of 5 , as pointed out by Rubin; see [52]. A correction was published by Statz and coworkers in J. Appl. Phys., vol. 39, July 1968 , pp. 4045-4046.

[45] T. Holstein, "Imprisonment of resonance radiation in gases, Part I," Phys. Rev., vol. 72, Dec. 15, 1947, pp. 1212-1233.

[46] - , Imprisonment of resonance radiation in gases, Part II, Phys. Rev., vol. 83, Sept. 15, 1951, pp. 1159-1168.

[47] E. I. Gordon, E. F. Labuda, R. C. Miller, and C. E. Webb, "Excitation mechanisms of the argon-ion laser," in Physics of Quantum Electronics, P. L. Kelly, B. Lax, and P. E. Tannenwald, Eds. New York: McGraw-Hill, 1966.

[48] P. O. Clark, W. B. Bridges, and A. S. Halsted, 1965 (unpublished).

[49] P. K. Cheo and H. G. Cooper, "Evidence for radiation trapping as a mechanism for quenching and ring-shaped beam formation in ion lasers," Appl. Phys. Lett., vol. 6, May 1, 1965, pp. 177-178.

[50] I. Gorog and F. W. Spong, "High pressure, high magnetic field effects in continuous argon ion lasers," Appl. Phys. Letl., vol. 9, July 1,1966 , pp. 61-63.

[51] K. G. Hernqvist and J. R. Fendley, Jr., "Construction of long life argon lasers," IEEE J. Quantum Electron., vol. QE-3, Feb. 1967, pp. 66-72.

[52] V. F. Kitaeva, A. N. Odintsov, and N. N. Sobolev, "Continuously operating argon ion lasers," Sov. Phys.-Usp., vol. 12, May-June 1970 , pp. 699-730.

[53] R. Paananen, "Continuously-operated ultraviolet lasers," Appl. Phys. Lett., vol. 9, July 1, 1966, pp. 34-35.

[54] K. Banse, H. Boersch, G. Herziger, G. Schäffer, and W. Seelig, "Hochleistungs-Ionenlaser," Z. Angew. Phys., vol. 26, Feb. 4, 1969, pp. 195-200.

[55] I. Gorog and F. W. Spong, "Experimental investigation of multiwatt argon lasers," RCA Rev., vol. 28, Mar. 1967, pp. 38-57.

\title{
A Surface-Charge Induction Motor
}

\author{
SOON DAL CHOI, MEMBER, IEEE, AND DONALD A. DUNN, SENIOR MEMBER, IEEE
}

\begin{abstract}
A motor that uses an electric field interaction with surface charges induced on the surface of a losey dielectric rotor as the force mechanism is described. A theory of force generation and officiency for a transverse-magnetic wave interaction with a moving conducting medium and a space-harmonic analysis of a practical circuit to carry such a wave are presented. A comparison is made between the results of this analysis and test results on a threo-phase $60-\mathrm{Hz}$ motor using a Bakelite or a Plexiglas rotor. Satisfactory agreement between theory and experiment is obtained in most respects. Motor operation was observed in both directions of rotation, as a result of interaction with the first beckward epace harmonic. Genorator operation is also theoretically possible and the theory for a single-harmonic-wave generator is presented. Generator operation was not observed, however, in the device that was teeted.
\end{abstract}

\section{INTRODUCTION}

$\bigwedge$ PUMPING effect in slightly conducting liquids due to an electrohydrodynamic traveling-wave interaction with induced surface charges on the liquid interface has been demonstrated by Melcher [1]. The mechanism by which his pump operated is directly analogous to that of the conventional induction motor [2] and the ac magnetohydrodynamic pump or generator [3]. These devices may be contrasted with ion-drag effect pumps [4] and related devices [5] such as conventional dc

Manuscript received February 24, 1970; revised September 29, 1970. This work was supported by the U. S. Army, Navy, and Air Force under Contract 225(83) with Stanford University, Stanford, Calif.

S. D. Choi is with the Jet Propulsion Laboratory, Pasadena, Calif.

D. A. Dunn is with the Institute for Plasma Research, Stanford University, Stanford, Calif. motors and generators and dc magnetohydrodynamic generators that require contact to be made between the working fluid or rotor and the stator [6].

Historically, interactions between rotating electric fields and dielectric solids and fluids date back to the work of Arno [7] in 1892. Theories of the force on spherical dielectric bodies in quadrupole fields were developed by Born [8] and Lertes [9] and experimental devices with this configuration were built by Grossetti [10] to test the properties of dielectric materials. Pickard [11] has made further contributions to the theory. A patent on a device using this principle has recently been issued to Fisher et al. [12]. The history of this subject has been reviewed by Melcher and Taylor [13]. The basic mechanism by which a force is generated involves the creation of surface charges on the dielectric rotor which have a relaxation time determined by the properties of the dielectric material. The surface-charge pattern has the same wavelength as the electric field that induces the charges and in the steady state is shifted in space phase with respect to the electric field by a phase angle that is determined by the relaxation time. Thus there is an optimum dielectric relaxation time for a given applied frequency.

The present study of the surface-charge induction motor follows directly from Melcher's [1] work. A relativistic analysis of such a device with a finite air gap has been carried out following previous work by Dunn, Wallace, and Choi [14] which assumed an infinitesimal air gap. A space- 


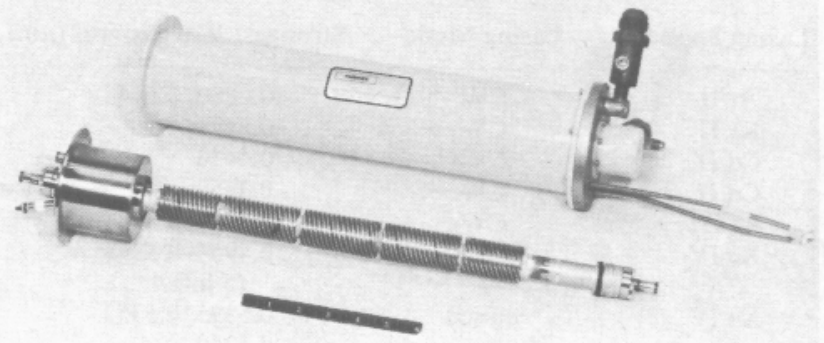

Fig. 1. A high-performance metal-ceramic argon ion laser discharge tube with its associated magnet. Metal cooling fins surround the ceramic section. (Hughes Electron Dynamics Division.) 

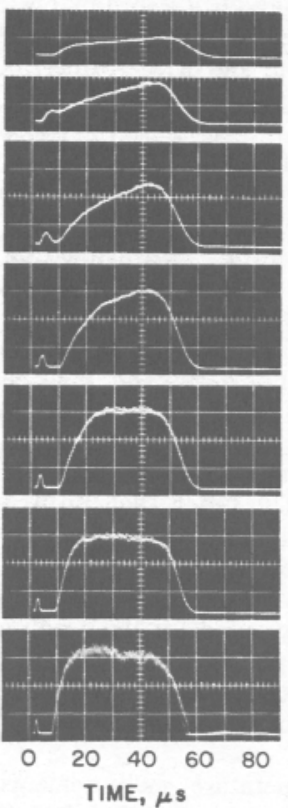

$75 \mathrm{~mA} \quad 25 \mathrm{~A}$

$125 \mathrm{~mA} \quad 41.7 \mathrm{~A}$

$150 \mathrm{~mA} 30 \mathrm{~A}$

$175 \mathrm{~mA} \quad 58.3 \mathrm{~A}$

AVERAGE PEAK $50 \mathrm{~mA} \quad$ 16.7A

$100 \mathrm{~mA} \quad 33.3 \mathrm{~A}$

200mA 66.7A

Fig. 10. Time variation of the $0.4880-\mu \mathrm{m}$ Ar II output in a small pulsed ion laser (2-mm diameter by $30 \mathrm{~cm}$ ) as the peak discharge current is increased. 